\title{
Factors Influencing Residents Dealing with Municipal Organic Waste in Developing Countries: Evidence from Rural Areas of Hoi An, Vietnam
}

\author{
Le Thi Thanh Loan ${ }^{1,2}$, Yoshifumi Takahashi ${ }^{1} \&$ Mitsuyasu Yabe ${ }^{1}$ \\ ${ }^{1}$ Laboratory of Environmental Economics, Department of Agricultural and Resource Economics, Faculty of \\ Agriculture, Kyushu University, Fukuoka City, Japan \\ ${ }^{2}$ Department of Agricultural Economics and Policies, Faculty of Economics and Rural Development, Vietnam \\ National University of Agriculture, Hanoi, Vietnam \\ Correspondence: Le Thi Thanh Loan, Laboratory of Environmental Economics, Department of Agricultural and \\ Resource Economics, Faculty of Agriculture, Graduate School of Bioresource and Bioenvironmental Sciences, \\ Kyushu University, 6-10-1, Hakozaki, Higashi-ku, Fukuoka City, Japan. Tel: 81-092-642-2960. E-mail: \\ thanhloan0209@gmail.com
}

Received: April 3, 2016 Accepted: May 3, 2016 Online Published: May 15, 2016

doi:10.5539/jas.v8n6p129 URL: http://dx.doi.org/10.5539/jas.v8n6p129

\begin{abstract}
Municipal solid waste (MSW) management in developing countries is facing many challenges. Most MSW is disposed of in landfill areas that are uncontrolled and overloaded. Under budget constraints, the governments encourage residents in rural areas to treat municipal organic waste (MOW) by themselves. Evidence from Hoi An, Vietnam has shown the potential for residents practicing MOW treatment at the source which may divert large quantities of biodegradable waste away from landfills. Logistic regression analysis showed that various factors influence residents treating MOW by themselves, including the gender of the person in charge of waste management, household size, presence of garden, type of city collection methods, care of collectors, and participation in compost training. Several factors are largely insignificant, including age, household income, number of children less than 15 years old, schooling years, and potential for high collection fees in the near future. The results further suggested that local authorities should encourage residents to practice MOW treatment at the source by enhancing the role of local women' groups, gardening clubs, composting training classes, and paying attention to communal collectors' roles.
\end{abstract}

Keywords: municipal solid waste, municipal organic waste treatment, landfill, waste reduction strategies

\section{Introduction}

\subsection{Municipal Organic Waste Definition and Issues}

Municipal organic waste (MOW) is biodegradable waste or the organic fraction of municipal solid waste (MSW). MOW primarily consists of food and yard waste generated by residential, commercial, institutional, and municipal service sources (Asian Development Bank, 2011; Rapport, Zhang, Jenkins, \& Williams, 2008). The generation of MSW has increased significantly because of the increasing population. It is estimated that 5.2 million tons of MSW are generated daily worldwide, of which around 3.8 million tons are generated by developing countries that contain 70\% of the MOW (Asian Development Bank, 2011). However, most of the MOW in this region is disposed of in uncontrolled and overloaded landfills since it remains the least expensive and easiest method to dispose of waste (Asian Development Bank, 2011; Buso, 2015; Institute for Global Environmental Strategies, 2008). Moreover, MSW collection rates are low (50\%-60\%), which can cause waste to be dumped into drains, rivers, and open spaces, causing pollution and health problems (Asian Development Bank, 2011).

Unlike other environmental issues, the public is not only concerned about MSW, but also able to be directly involved in its solution. For instance, residents may participate in waste management activities as they minimize the amount of MSW that needs to be disposed of (Lober, 1996). Recycling is one method of reducing waste that reaches the landfill. In this method, residents recycle MOW via home composting to turn waste into a resource. This activity is completely in the hands of residents (Tucker \& Speirs, 2001). Determining the factors that affect 
residents' decisions regarding how they deal with MOW plays an important role in MSW management in all countries, especially developing countries that commonly face environmental problems.

\subsection{MOW Situation in Hoi An, Vietnam}

The landfill serving Hoi An in Quang Nam province, Vietnam will be closed in the short term because it was poorly designed, uncontrolled and overloaded (Trinh, 2015). This closure may also influence the development of tourism in the city. Moreover, budget constraints have resulted in the city being able to collect $95 \%-100 \%$ of the garbage in urban areas, but only a portion of the waste in rural areas (Trinh, 2015). Amidst these problems, the local authority stipulates that MSW reduction is one of the main tasks associated with environmental protection strategies. The residents in rural areas have been encouraged to deal with MOW by treating it at the source to reduce the amount of MOW that needs to be disposed of.

To the best of our knowledge, no specific studies have considered the decision of rural residents to deal with MOW. The residents may dispose of MOW through collectors or they responded positively to a local authority campaign that encourage them treating MOW at source. The present study makes a unique contribution to understanding rural residents' decisions regarding how they deal with MOW at the source. In particular, the study centers on factors influencing rural residents dealing with MOW at a household level.

\section{Method}

\subsection{Study Site}

Hoi An in Quang Nam province is located in central Vietnam. The city attracts tourists from worldwide because of its history and beauty. Around 68.97 tons of MSW composed of $53.12 \%$ organic matter are generated per day by 91,993 residents, restaurants, hotels, and municipal services. The large amount of MSW generated threatens this relatively small city (Hoi An Statistical Office, 2014; Trinh, 2015). The main collection and treatment of the MSW is the responsibility of the municipal services. MSW collection methods include door to door collection services by city collectors with compactors and communal collectors that use hand trucks.

In recent years, Hoi An has adopted an MSW minimization strategy from Naha, Japan that recommends residents apply the 3Rs (Reduce, Reuse, and Recycle). Additionally, the local authority has campaigned to encourage residents in rural areas to treat MOW by themselves to reduce the large amount of MOW that needs to be collected and treated at the city level.

\subsection{Sampling}

Primary data were collected by conducting a survey and personal interviews of residents in the rural areas of Hoi An. Overall, 204 respondents were approached and 202 questionnaires were considered as valid cases $(99 \%$ of the respondents). Respondents were only selected if they were in charge of waste management in their houses. The questionnaire was conducted using information regarding residents' socio-demographic characteristics, environmental and social attitude, and MOW treatment practices, and asked them the major decision to deal with MOW.

\subsection{Empirical Analysis}

To determine the factors affecting decisions made by residents regarding how they deal with MOW at source, we considered the appropriate empirical analysis model for the study. Since the respondents have binary choices, the individual faces a pair of choices. The response variable was whether or not MOW was dealt with by treatment at the source, which is a dichotomous dependent variable. The two most popular forms are the logistic function, which is used in logit estimation, and the cumulative normal distribution, which is used in probit estimation. When determining which model to use in this study, logit and probit analysis yielded similar marginal effects in most applications, and the outcomes were similar (Dougherty, 2011).

In this study, logistic regression analysis was applied to explain the behavior of a dichotomous dependent variable. The formula of this model was as follows:

$$
\ln \left[P_{i} / 1-P_{i}\right]=\beta_{0}+\beta_{i} X_{i}+e_{i}
$$

Where,

$P_{i}=1$ if treatment at the source is the respondent's major decision to deal with MOW;

$P_{i}=0$ if the respondent's major decision to deal with MOW is disposing of waste to the municipality;

$\beta_{0}$ is the parameter vector to be estimated;

$\beta_{i}$ is the coefficient of independent variables; 
$X_{i}$ is a vector of explanatory variable observations;

$e_{i}$ is a random error term.

The following are the explanatory variables that were included in the logit model: socio demographic characteristic variables such as gender of respondent, age, income, number of children less than 15 years old, household size, number of schooling years, presence of garden (dummy), fond of gardening (dummy), care of MOW collectors (dummy), participation in compost training (dummy), concern about increasing MSW collection fee (dummy), and local community MSW management features such as a MOW collector (dummy).

The marginal effects explain the probability of rural residents practicing MOW treatment at the source. Marginal effects are the change in predicted probability associated with changes in explanatory variables of the logit model (Anderson \& Newell, 2003; Green, 2003). In the case of the model given above, marginal effects are interpreted as the effect of a unit change in a regressor on the probability that a respondent will treat MOW at the source.

Both coefficients of the binary logit model and marginal effects were estimated using the STATA 12.0 program.

\section{Results}

\subsection{Socio Demographic Characteristic of Respondents and Variables Used in the Logistic Regression Analysis}

The dependent and explanatory variables of the model, and their summary statistics are presented in Table 1.

Table 1. Description of socio demographic characteristics of respondents and variables used in the logistic regression model

\begin{tabular}{llll}
\hline Variable name & Description & Mean & SD \\
\hline Dtreatment & $\begin{array}{l}\text { 1 if treatment at the source is the major decision to deal with MOW. 0 } \\
\text { if the major decision to deal with MOW is disposing to the } \\
\text { municipality }\end{array}$ & 0.64 & 0.48 \\
Female & Gender of respondents (1 if female, 0 otherwise) & 47.61 & 0.44 \\
Age & Actual age of respondents (years) & 6,233 & 3,410 \\
Income & Household income per month (1,000 VND $)^{\mathrm{a}}$ ) & 0.98 & 0.94 \\
Child & The number of children less than 15 years old & 4.46 & 1.50 \\
Hhsize & Household size (persons) & 6.74 & 3.74 \\
School & Number of years of schooling (years) & 0.64 & 0.48 \\
Garden & 1 if the house has a garden, 0 if otherwise & 0.68 & 0.47 \\
Fond & 1 if the respondent is fond of gardening, 0 if otherwise & 0.47 \\
Care & 1 if the respondent cares for MSW collectors, 0 if otherwise & 0.22 & 0.50 \\
Training & 1 if the respondents participated in compost training, 0 if otherwise & 0.42 \\
IncrFEE & 1 if the respondent is concerned with increasing the MSW collection & 0.30 & 0.46 \\
Collector & fee, 0 if otherwise & & 0.66 \\
\hline
\end{tabular}

Note. ${ }^{\mathrm{a}} 1 \mathrm{USD}=22,000 \mathrm{VND}$.

As shown in Table 1, treatment at the source is the main decision of respondents to deal with MOW at the household level in rural areas of Hoi An (64\%). The socio-economic backgrounds of the respondents are shown in Table 1. In this sample, $74 \%$ of respondents were female and $26 \%$ were male. The mean actual age of respondents is approximately 48 years. The household respondents earned 6,233 thousand VND per month on average. The average household size of sampling was 4.46 and the average number of children less than 15 years old in their family was 0.98 . The respondents had average schooling years of 6.74 . Overall, $64 \%$ of respondents have gardens in their house and $68 \%$ are fond of gardening. Additionally, $47 \%$ of respondents care for MOW collectors. Overall, $22 \%$ of respondents participated in the compost training program organized by local authorities, while $30 \%$ of respondents were concerned with increasing MSW collection fees in the near future and $66 \%$ of respondents answered that their garbage was collected by local community collectors. 


\subsection{Empirical Results}

The coefficients in the model were estimated using the maximum likelihood estimation method with the STATA econometrics software. Logistic regression analysis revealed that multicollinearity may be a problem if causing bias estimation. Therefore, we tested multicollinearity in two ways. First, we tested correlations between all pairs of independent variables. The results showed that all correlations are less than 0.8 . We then tested the multicollinearity through Variance Inflation Factors (VIF) for the independent variables. All VIF values were less than 10 and the mean VIF was equal to 1.33 , which strongly confirms that multicollinearity among combinations of independent variables was not a problem for the model (Appendix A). Maximum likelihood estimates of parameters used in the logistic regression analysis are presented in Table 2.

Table 2. Logit estimation for MOW treatment in Hoi An

\begin{tabular}{|c|c|c|c|}
\hline Variables & Coef. & $z$-Test & Marginal effect (dy/dx) \\
\hline Constant & -6.24 & -3.97 & - \\
\hline Female & $0.89^{*}$ & 1.87 & $0.16^{*}$ \\
\hline Age & 0.03 & 1.64 & 0.01 \\
\hline Income & 0.00 & 0.44 & 0.00 \\
\hline Child & -0.06 & 0.84 & -0.01 \\
\hline Hhsize & $0.26^{*}$ & 1.71 & $0.043^{*}$ \\
\hline School & 0.05 & 0.80 & 0.01 \\
\hline Garden & $0.76^{*}$ & 1.75 & $0.13^{*}$ \\
\hline Fond & $1.16^{* *}$ & 2.49 & $0.21^{* *}$ \\
\hline Care & $1.42^{* * * *}$ & 3.00 & $0.23^{* * *}$ \\
\hline Training & $4.36^{* * *}$ & 3.49 & $0.40^{* * *}$ \\
\hline IncrFEE & 0.70 & 1.54 & 0.12 \\
\hline Collector & $1.01^{* *}$ & 2.41 & $0.18^{* \pi}$ \\
\hline Pseudo $\mathrm{R}^{-}$ & 0.38 & & \\
\hline Log likelihood & -82.20 & & \\
\hline LR chi2 & 99.91 & & \\
\hline Prob $>$ chi 2 & 0.000 & & \\
\hline
\end{tabular}

Female has a positive significant impact on MOW treatments by households. For every one person in charge with female garbage management, the possibility of dealing with MOW treatment at the source will increase by 0.163

Household size has a positive significant effect on the household decision to practice garbage treatments. When household size increases by one person, the residents will more likely practice garbage treatment at the source by 0.043 .

Garden is significant at the $10 \%$ level. Respondents who had gardens were $13 \%$ more likely to practice garbage treatment. The predictor fond of gardening has a significant effect on the respondents' decisions for MOW treatments. People most interested in gardening will more likely treat MOW at the household level by 0.21 .

Care for garbage collectors will push the residents more likely practice the garbage treatment at source by 0.22 . Participation in compost training program in the city was encouraged the residents more likely treat the MOW waste by 0.40 .

Collector was found to be a significant predictor of residents practicing MOW treatment at the source. This factor can interpret whether residents who have MOW collected by the communal collectors will more likely treat MOW at the source by 0.18 .

Outcome of the study show that socio characteristics of respondents such as age, income, years attending school, and the number of children and concern about increasing collection fees generally had no effect on garbage treatment decisions. 


\section{Discussion}

This study is the first attempt to investigate factors influencing the decision of residents to deal with MOW in rural areas of developing countries. The results have shown the potential for residents to treat MOW at the source in Hoi An, Vietnam by approximately $64 \%$.

Regression analysis was conducted to identify significant variables affecting the respondents' decisions to deal with MOW. Being female was found to have significant positive effects. If the person in charge of waste management is female, the likelihood of treating MOW at the source will increase. The women' unions or women'groups plays an important role in waste reduction strategies of Hoi An, where the female respondents have a chance to participate in many training activities and access the information from the city's campaign. This finding was consistent with the contribution from waste management research in the Philippines. Additionally, the mothers' of households played significant roles in household waste management (Bennagen, Nepomuceno, \& Covar, 2002).

Age, income and school were found to have nonsignificant effects on residents practicing MOW treatment at the source. These findings are consistent with those of a study conducted by Tadesse et al.(2008), who concluded that the demographic variables age and school did not have a significant impact on the selection of waste disposal method in Ethiopia. Age and income also had no significant effect on home composting in Metro Manila, Philippines (Bennagen et al., 2002). Other findings in the environmental literature also confirmed the relatively limited utility of demographic variables as predictors of environmental concern (Lober, 1996).

Previous studies showed that a family with young children is less likely to participate in the home composting scheme (Edgerton et al., 2008). In the present study, the coefficient of the predictor Child is negative. These findings are consistent with those of previous studies that showed families with more young children less than 15 years old will be less likely to practice treatment of MOW at the source. However, this predictor was found to have non-significant effects on the decisions residents make regarding MOW. Household size had a significant effect on residents dealing with MOW in Hoi An. These findings are opposite of those from the Philippines since household size cannot predict the behavior of residents composting MOW at the source. However, in the case we observed, the predictor was only significant at the $10 \%$ level.

The absence of a garden or yard prevents residents from treating MOW. In the case of Hoi An, garden was a significant predictor for MOW treatment at the source. Residents treat MOW by digging holes in the garden, burying garbage, and growing plants on the land surface. These findings are similar to those for Metro Manila in the Philippines (Bennagen et al., 2002). In the case of Cebu, Philippines, many respondents felt that composting at the household level did not fit with their living conditions, especially the lack of space for gardening and close proximity of the neighbors (Premakumara, 2011).

Fondness of gardening was positively associated with respondent's treatment of MOW at the source. Bennagen et al. (2002) found that $35 \%$ of respondents engaged in composting because they were fond of gardening. Treatment of MOW at the source can enhance garden soil or be considered a horticultural recreational activity (Andersen, Boldrin, Christensen, \& Scheutz, 2011; Bennagen et al., 2002). These results suggest that the local government can introduce and support fond of gardening clubs to encourage more residents to participate in the program. The local government should keep guiding the residents to not only treat the garbage, but also to optimize the safe fertilization of gardens.

Care for collectors was found to be a significant predictor of residents treating MOW instead of disposing of it to the municipality. In fact, waste collectors are at risk for work related disorders and injuries (Kuijer et al., 2010). Many respondents care for garbage collectors, and they might decide to reduce the amount of waste disposal through MOW treatment at the source.

Training was found to be significant predictor of residents treating MOW at the household level. These findings are similar to those of other studies that showed training plays an important role for introducing advanced technology to rural residents (Trinh, 2015; Hussain et al., 1994; Neupane et al., 2002).

The present study asked the respondents whether they practice treatment of MOW at the source to avoid the collection fee increasing in the future. However, the predictor IncrFEE was not significant in the case we observed in Hoi An. These results are concordant with those reported by Bennagen et al. (2002), who found that treating MOW by methods such as composting was not done for financial reasons.

Interestingly, the variable collector was found to have a positive significant effect. Residents who have MOW collected by communal collectors were more likely to treat the MOW at source in comparision with city collectors. The communal collectors are local residents who have closer relationships with the respondents and 
therefore might always remind the residents to reduce garbage disposal and try their best to recycle the waste. Thus, the city should provide notices to communal collectors to support their potential roles.

\section{Conclusion}

This study provides an interesting image of MOW treatment practices in rural areas of Hoi An that may potentially divert large quantities of biodegradable waste away from landfills. The results reported herein revealed the successful reduction of MSW strategies in the city by $64 \%$ of respondents practicing MOW treatment at the source. Empirical analysis using logistic regression analysis showed that being female, household size, fondness of gardening, presence of garden, participation in compost training, type of city collection methods, and care of collectors were significant factors. The local government should encourage residents to practice MOW treatment at the source by enhancing the role of women's unions, gardening clubs, composting training/classes and paying attention to communal collectors' roles.

\section{Acknowledgements}

Supports for this work from Hoi An Public Works Joint Stock Company, Department of Natural Resources and Environment of Hoi An city are gratefully acknowledged. We are thankful to Mr. Pham Phu Song Toan and the students from Danang University for their kind help during our surveys in Hoi An city. We are grateful to Laboratory of Environmental Economics, Kyushu University for providing facilities to conduct the research. The financial support from the Setsutaro Kobayashi Memorial Fund 2015 is gratefully acknowledged.

\section{References}

Andersen, J. K., Boldrin, A., Christensen, T. H., \& Scheutz, C. (2011). Mass balances and life cycle inventory of home composting of organic waste. Waste Management, 31(9-10), 1934-1942. http://dx.doi.org/10.1016/j.wasman.2011.05.004

Anderson, S., \& Newell, R. (2003). Simplified Marginal Effects in Discrete Choice Models. Discussion Paper, Published by Resources for the Future. http://dx.doi.org/10.1016/s0165-1765(03)00212-x

Asian Development Bank. (2011). Toward sustainable municipal organic waste management in South Asia. Retrieved from http://www.adb.org/sites/default/files/publication/29082/sustainable-waste-managementsouth-asia.pdf

Bennagen, M. E. C., Nepomuceno, G., \& Covar, R. (2002). Recycling in Iietro Ilanula: Household Attitudes and Behavior Sereatiori arid Manila: Household Attitudes and Behavior. Published by Economy and Environment Program for Southeast Asia.

Buso, S. (2015). Environmental and community impacts of waste disposal in OR Tambo District Municipality (South Africa). Sustainable Development and Planning VII, 193, 509-520. http://dx.doi.org/10.2495/SDP150441

Premakumara, D. G. J. (2011). Survey of Household Solid Waste Generation and Public Awareness on Waste Separation and Compositing Practices in Cebu City, 97. Published by Institute for Global Environmental Strategies.

Dougherty, C. (2011). Introduction to Econometrics (4th ed.). Oxford University Press.

Edgerton E., McKechnie, J., \& Dunleavy, K. (2008). Behavioral Determinants of Household Participation in a Home Composting Scheme. Environment and Behavior, 41(2), 151-169. http://dx.doi.org/10.1177/0013916 507311900

Green, W. H. (2003). Econometric Analysis. Prentice Hall, USA.

Hoi An Statistical Office. (2014). Hoi An statistical yearbook 2011.

Hussain, S. S., Byerlee, D., \& Heisey, P. W. (1994). Impacts of the training and visit extension system on farmers' knowledge and adoption of technology: Evidence from Pakistan. Agricultural Economics, 10(1), 39-47. http://dx.doi.org/10.1016/0169-5150(94)90038-8

Institute for Global Environmental Strategies. (2008). Climate change policies in the Asia-Pacific: Re-uniting climate change and sustainable development.

Kuijer, P. P. F. M., Sluiter, J. K., \& Dresen, M. H. W. F. (2010). Health and safety in waste collection: Towards evidence-based worker health surveillance. American Journal of Industrial Medicine, 53, 1040-1064. http://dx.doi.org/10.1002/ajim.20870

Lober, D. J. (1996). Municipal solid waste policy and public participation in household source reduction. Waste 
Management \& Research, 14, 125-143. http://dx.doi.org/10.1177/0734242X9601400203

Neupane, R. P., Sharma, K. R., \& Thapa, G. B. (2002). Adoption of agroforestry in the hills of Nepal: A logistic regression analysis. Agricultural Systems, 72(3), 177-196. http://dx.doi.org/10.1016/S0308-521X(01) 00066-X

Rapport, J., Zhang, R., Jenkins, B. M., \& Williams, R. B. (2008). Current Anaerobic Digestion Technologies Used for Treatment of Municipal Organic Solid Waste (p. 69). http://dx.doi.org/10.1016/j.biortech.2006.11.048

Tadesse, T., Ruijs, A., \& Hagos, F. (2008). Household waste disposal in Mekelle city, Northern Ethiopia. Waste Management, 28(10), 2003-2012. http://dx.doi.org/10.1016/j.wasman.2007.08.015

Tucker, P., \& Speirs, D. (2001). Understanding Home Composting Behaviour. Technical Monograph. Retrieved from http://www.uws.ac.uk/workarea/downloadasset.aspx?id=2147494969

Trinh, C. M. (2015). Report on waste management in Cam Ha and Cam Pho commune, Hoi An city. 


\section{Appendix}

\section{Appendix A. Test for multicollinearity}

Table A1. Results of correlation test

\begin{tabular}{|c|c|c|c|c|c|c|c|c|c|c|c|c|}
\hline $\begin{array}{l}\text { Independent } \\
\text { variables }\end{array}$ & Female & Age & Income & Child & Hhsize & School & Training & Garden & Fond & Collector & Care & incrFEE \\
\hline Female & 1.00 & & & & & & & & & & & \\
\hline Age & -0.09 & 1.000 & & & & & & & & & & \\
\hline Income & 0.10 & -0.10 & 1.00 & & & & & & & & & \\
\hline Child & 0.06 & -0.24 & 0.15 & 1.00 & & & & & & & & \\
\hline Hhsize & 0.06 & -0.04 & 0.23 & 0.50 & 1.00 & & & & & & & \\
\hline School & -0.08 & -0.42 & 0.25 & 0.15 & 0.13 & 1.00 & & & & & & \\
\hline Training & -0.09 & -0.06 & 0.01 & 0.09 & -0.11 & 0.13 & 1.00 & & & & & \\
\hline Garden & -0.04 & 0.09 & 0.01 & -0.13 & 0.03 & 0.06 & 0.17 & 1.00 & & & & \\
\hline Fond & 0.11 & 0.11 & 0.02 & -0.19 & -0.08 & -0.06 & 0.13 & 0.43 & 1.00 & & & \\
\hline Collector & 0.05 & 0.01 & -0.02 & -0.09 & -0.05 & 0.11 & 0.24 & 0.03 & 0.07 & 1.00 & & \\
\hline Care & 0.08 & 0.08 & -0.06 & -0.24 & -0.11 & 0.04 & 0.16 & 0.27 & 0.37 & 0.39 & 1.00 & \\
\hline incrFEE & -0.04 & -0.08 & 0.02 & 0.05 & -0.02 & -0.03 & -0.09 & -0.06 & 0.00 & -0.10 & -0.31 & 1.00 \\
\hline
\end{tabular}

Source: Authors' estimation.

Table A2. Results of Variance Inflation Factors (VIF) test

\begin{tabular}{lll}
\hline Variables & VIF & $1 / \mathrm{VIF}$ \\
\hline care & 1.59 & 0.63 \\
child & 1.57 & 0.64 \\
hhsize & 1.47 & 0.68 \\
fond & 1.42 & 0.70 \\
school & 1.39 & 0.72 \\
age & 1.33 & 0.75 \\
garden & 1.32 & 0.76 \\
collector & 1.26 & 0.79 \\
training & 1.20 & 0.83 \\
incrFEE & 1.14 & 0.88 \\
income & 1.14 & 0.88 \\
female & 1.09 & 0.91 \\
Mean VIF & 1.33 & \\
\hline
\end{tabular}

Source: Authors' estimation.

\section{Copyrights}

Copyright for this article is retained by the author(s), with first publication rights granted to the journal.

This is an open-access article distributed under the terms and conditions of the Creative Commons Attribution license (http://creativecommons.org/licenses/by/3.0/). 